\title{
Danggui-Jakyak-San ameliorates memory impairment and increase neurogenesis induced by transient forebrain ischemia in mice
}

\author{
Mi Deok Song ${ }^{1}$, Dong Hyun Kim², Jong Min Kim², Hyung Eun Lee², Se Jin Park², Jong Hoon Ryu ${ }^{2,3^{*}}$
} and Jae Hwan Lew ${ }^{1 *}$

\begin{abstract}
Background: Danggui-Jakyak-San (DJS), a traditional herbal prescription, has been used to treat insufficient blood supplies. Recently, regenerative medication for the treatment of cerebral ischemia has drawn the attention of many researchers.

Methods: In this study, we examined whether DJS exerts a neuronal regenerative effect in the hippocampus of a transient forebrain ischemia mice model. Transient forebrain ischemia was induced by bilateral common carotid artery occlusion (BCCAO). Animals were divided into three groups (sham, BCCAO + vehicle, and BCCAO + DJS). To test the effect of DJS on learning and memory, Morris water maze or passive avoidance test was conducted. To test neuroprotective and neurogenic effect, immunohistochemistry and Western blot analysis were used. Statistical significance was analyzed with Student $t$-test, one-way or two-way analysis of variance.

Results: We found that the administration of DJS ameliorated ischemia-induced spatial memory impairment in the

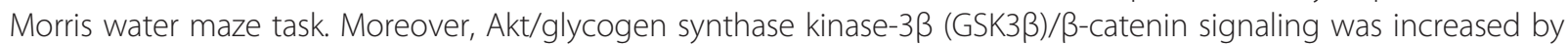
DJS, which would be one possible mechanism of DJS for neurogenesis in the hippocampal dentate gyrus region.

Conclusions: These results suggest that DJS is a possible candidate for the treatment of ischemia-induced neuronal degeneration.
\end{abstract}

Keywords: Danggui-Jakyak-San, Transient forebrain ischemia, Neurogenesis, GSK-3 $\beta$, $\beta$-catenin, Hippocampus

\section{Background}

Neurogenesis in subgranular zone of hippocampus and the subventricular zone is affected by various physical, pharmacological, and pathological conditions, specifically including ischemic stroke and seizure [1,2]. Because of the regional correlation, neurogenesis in the hippocampal dentate gyrus (DG) has been studied in various disorders that cause memory impairment. As a result of these efforts, many anti-depressants or mood stabilizers have already been found to improve the neurological outcomes through an increase in neurogenesis in ischemic

\footnotetext{
* Correspondence: jhryu63@khu.ac.kr; intmed@khu.ac.kr

${ }^{2}$ Department of Life and Nanopharmaceutical Sciences, Kyung Hee

University, Seoul 130-701, Republic of Korea

${ }^{1}$ Graduate School of East-west Medical Science, Kyung Hee University,

Yongin 446-701, Republic of Korea

Full list of author information is available at the end of the article
}

stroke models, including the enhancement of learning and memory, mood stability, and motor function [3].

Dangui-Jakyak-San (Danggui-Shaoyao-San in Chinese; Toki-Shakuyaku-San in Japanese; DJS) is an herbal prescription that consists of Paeoniae Radix, Atractylodis Rhizoma, Alismatis Rhizoma, Hoelen, Cnidii Rhizoma, and Angelicae Gigantis Radix. DJS has been widely used in the treatment of various types of diseases [4,5]. Previous clinical reports demonstrated that DJS has effects on the mild cognitive impairment [6] and functional deficits in post-stroke patients [7]. DJS also showed improvements of spatial cognition impairment $[8,9]$ and dysfunction of central cholinergic nervous system [10] in animal models. Moreover, DIS has neuroprotective effects in vitro system $[11,12]$. However, functional mechanisms of the effect of DJS on various neurological deficits are still not clarified. 
In a preliminary study, we found that long-term administration of DJS enhances learning and memory in normal naïve mice and increases neurogenesis in the hippocampus. Based on these findings, we speculated that DJS may improve the functional outcomes in an ischemic model through neurogenesis-induced neuronal regeneration. In a pilot study, the most effective dose of DJS was $100 \mathrm{mg} / \mathrm{kg}$, and we adopted this dose for further experiments. We observed that delayed long-term treatment with DJS ameliorates the memory impairment induced by transient forebrain ischemia and that this effect may be due to the enhancing effects of DJS on neurogenesis.

\section{Methods}

Animals

Male C57BL/6 mice (22-26 g, 7 weeks) were purchased from the Orient Co. Ltd, a branch of Charles River Laboratories (Seoul, Korea), and kept in the University Animal Care Unit for 1 week prior to the experiments. The animals were housed 5 per cage, allowed access to water and food ad libitum; the environment was maintained at a constant temperature $\left(23 \pm 1^{\circ} \mathrm{C}\right)$ and humidity $(60 \pm 10 \%)$ under a 12-h light/dark cycle (the lights were on from 07:30 to 19:30 h). Thirty mice were divided equally into three groups (sham, $\mathrm{n}=10$; bilateral common carotid artery occluded ischemia + vehicle, $n=10$; bilateral common carotid artery occluded ischemia + DJS, $\mathrm{n}=10$ ) for behavioral tests. The treatment and maintenance of the animals were carried out in accordance with the Animal Care and Use Guidelines of Kyung Hee University, Korea. All of the mouse experiments were performed according to the protocols approved by the Institutional Animal Care and Use Committee of Kyung Hee University (approved protocol numbers: KHP-2010-6-4; KHP-2010-8-11).

\section{Materials}

5-Bromo-2' -deoxyuridine (BrdU) and crezyl violet were purchased from Sigma Chemical Co. (St. Louis, MO). Zoletil $50^{\circledR}$ was obtained from the Virbac laboratory (06516 Carros, France). The Complete Protease Inhibitor Cocktail and PhosSTOP Phosphatase Inhibitor Cocktail were purchased from Roche (Palo Alto, CA). The rat monoclonal anti-BrdU (ab6326) and rabbit polyclonal anti-Ki-67 (ab15580) antibodies were purchased from Abcam (Cambridge, UK). The goat polyclonal antidoublecortin (DCX, sc-8066), rabbit polyclonal antiAkt (sc-8312), goat polyclonal anti-tubulin (sc-9935), and goat polyclonal anti-GSK3 3 (sc-8257) antibodies were purchased from Santa Cruz Biotech (Santa Cruz, CA). The mouse monoclonal anti-NeuN (MAB377) and rabbit monoclonal anti-GFAP (AB5804) antibodies were purchased from Millipore (Temecula, CA). The rabbit polyclonal anti-pAkt (\#9271), anti-pGSK3ß (\#9323), and anti- $\beta$-catenin (\#9582) antibodies were purchased from Cell Signaling Technology Inc. (Danvers, MA). The avidin-biotin-peroxidase complex (ABC) kit was purchased from Vector Laboratories, Inc. (Burlingame, CA). All of the other materials were of the highest grade available and were obtained from normal commercial sources.

\section{Preparation of herbal extracts}

The herbal materials [Paeoniae Radix (Paeonia lactiflora Pall, Paeoniaceae), Atractylodis Rhizoma (Atractylodes japonica Koidzmi, Compositae), Alismatis Rhizoma (Alisma orientalis Juzep, Alismataceae), Hoelen (Poria cocos Wolf, Polyporaceae), Cnidii Rhizoma (Cnidium officinale Makino, Umbelliferae), and Angelicae Gigantis Radix (Angelica gigas Nakai, Umbelliferae)] were purchased from the Kyungdong oriental drug store (Seoul, Korea) and identified by emeritus professor Chang Soo Yook, College of Pharmacy, Kyung Hee University. The DJS was prepared by boiling Paeoniae Radix (4 g), Atractylodis Rhizoma (4 g), Alismatis Rhizoma (4 g), Hoelen (4 g), Cnidii Rhizoma (3 g), and Angelicae Gigantis Radix (3 g) in 10 volumes of water. The aqueous solutions obtained were filtered, concentrated in a water bath under vacuum, frozen, lyophilized (Eyela, model FDU-2000, Japan), and stored at $-20^{\circ} \mathrm{C}$ until required (yield; 12.3\%). Paeoniflorin in Paeoniae Radix, ferulic acid in Cnidii Rhizoma, and decursin in Angelicae Gigantis Radix were used to ensure preparation consistencies. Paeoniflorin, ferulic acid, and decursin were present in DJS at $1.76 \%, 0.09 \%$, and $0.38 \%$, respectively.

\section{Passive avoidance test}

To investigate memory enhancing effects of DJS, the acquisition and retention of passive avoidance behavior were conducted. The animals underwent two separated trials, an initial acquisition trial and a retention trial $24 \mathrm{~h}$ later. For the acquisition trial, a mouse was initially placed in the light compartment, and the door between the two compartments was opened $10 \mathrm{~s}$ later. When the mouse entered the dark compartment, the guillotine door automatically closed and an electrical foot shock $(0.25 \mathrm{~mA}, 3 \mathrm{~s})$ was delivered through the floor. For the retention trial, the mouse was again placed in the light compartment and the time required to enter the dark compartment was recorded. Mice were treated with DJS for 14 days and introduced into the acquisition trial $1 \mathrm{~h}$ after the last administration.

\section{Surgery and drug administration}

C57BL/6 mice were anesthetized with $2.0 \%$ isoflurane and $70 \%$ nitrous oxide in oxygen and subjected to transient forebrain ischemia. The transient forebrain ischemia was induced by bilateral common carotid artery 
occlusion (BCCAO) with aneurysm clips for $20 \mathrm{~min}$, and the circulation was restored by removing the clips. Mice that received the same surgical operation without carotid artery clipping served as sham-operated controls. During the surgical procedure, the rectal temperature was maintained at $37 \pm 0.5^{\circ} \mathrm{C}$ with a heating pad (Biomed S.L., Spain). The regional cerebral blood flow (rCBF) was monitored using laser Doppler flowmetry (Perimed, PF5010, JarFalla, Sweden). The mice that showed between $80 \%$ and $95 \%$ reduction of $\mathrm{rCBF}$ were used in the study. After reperfusion, the animals were placed in a warm incubator $\left(32-33^{\circ} \mathrm{C}\right)$ and returned to their home cages. DJS, which was dissolved in $10 \%$ Tween 80 solution, was administered from 7 days to 35 days after BCCAO $(100 \mathrm{mg} / \mathrm{kg}$, p.o., once daily) in the BCCAO + DJS group. BCCAO + vehicle group was administered with the same schedule with vehicle (10\% Tween 80 solution) instead of DJS.

\section{Morris water maze task}

The Morris water maze task was conducted from 30 to 35 days after BCCAO and started $1 \mathrm{~h}$ after the administration of DJS. The first experimental day was dedicated to swim training for $60 \mathrm{~s}$ in the absence of the platform. During the four subsequent days, the mice were given one trial per session per day with the platform in place to avoid the ceiling effects induced by four trials per session. The starting point was changed for each training trial day. When a mouse located the platform, it was permitted to remain on it for $10 \mathrm{~s}$. If the mouse did not locate the platform within $120 \mathrm{~s}$, it was placed on the platform for $10 \mathrm{~s}$. The animal was taken to its home cage and was allowed to dry off under an infrared lamp after each trial. During each trial, the time taken to find the hidden platform (escape latency) was recorded using a video camera-based Ethovision System (Nodulus, Wageningen, The Netherlands). One day after the last training trial, the mice were subjected to a probe trial session in which the platform was removed from the pool, allowing the mice to swim for $120 \mathrm{~s}$ to search for it. A record was kept of the swimming time in the pool quadrant where the platform had previously been placed.

\section{BrdU treatment and tissue preparation}

Normal naive mice without introduction into BCCAO were treated with DJS for 14 days, and the mice were anesthetized with Zoletil $50^{\circledR}(10 \mathrm{mg} / \mathrm{kg}$, i.m.) and then perfused transcardially with a $100 \mathrm{mM}$ phosphate buffer ( $\mathrm{pH}$ 7.4) followed by ice-cold 4\% paraformaldehyde. The brains of the mice were removed and postfixed in a phosphate buffer (50 mM, pH 7.4) containing 4\% paraformaldehyde overnight, then immersed in a $30 \%$ sucrose solution (in $50 \mathrm{mM}$ phosphate-buffered saline, PBS),

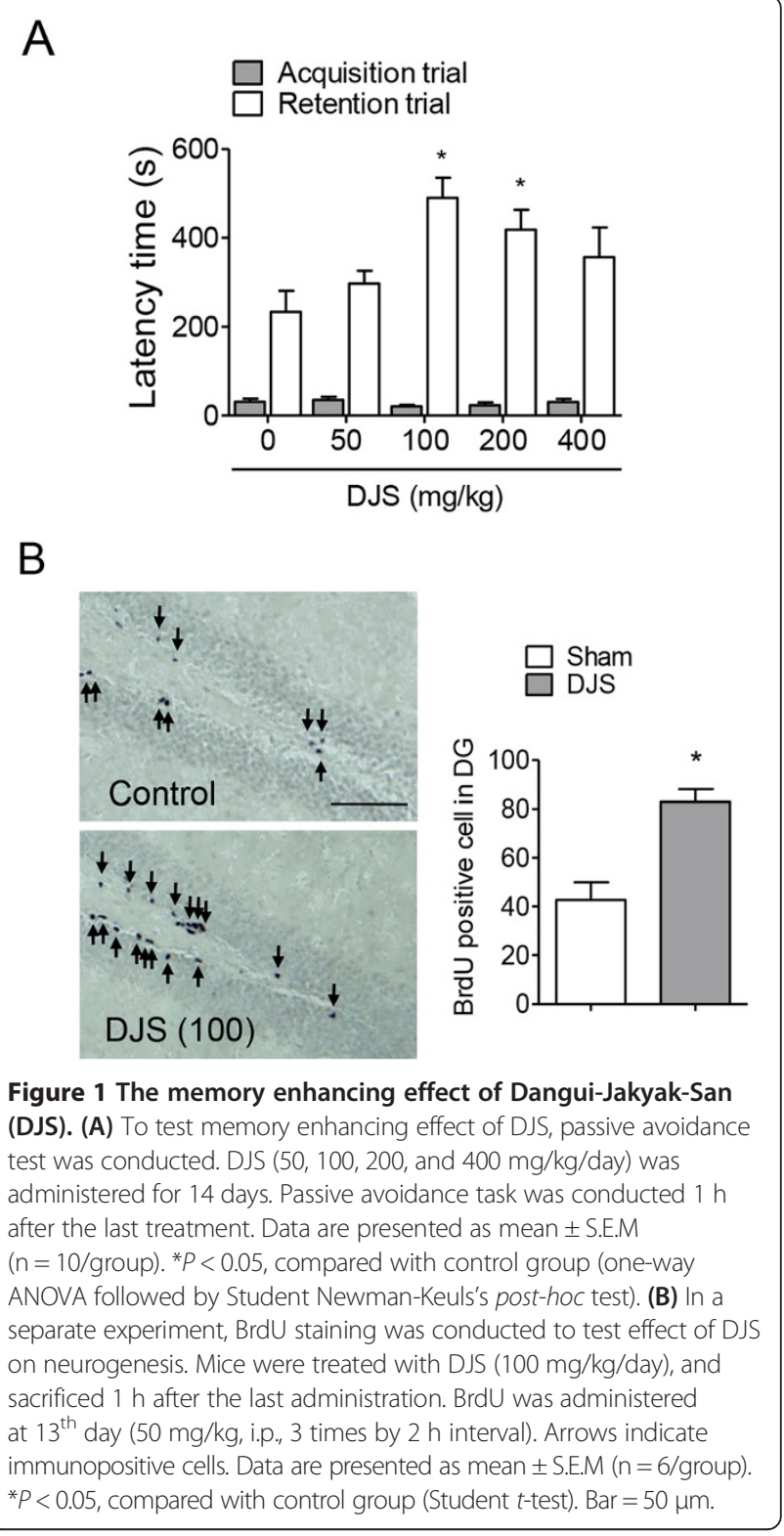

and stored at $4^{\circ} \mathrm{C}$ until sectioned. BrdU $(50 \mathrm{mg} / \mathrm{kg}$, i.p., 3 times by $2 \mathrm{~h}$ interval) was administered at $13^{\text {th }}$ day. In the ischemia experiment, mice were injected with BrdU (50 mg/kg, i.p., 3 times by $2 \mathrm{~h}$ interval) 7 days after BCCAO. Six mice in each group were anesthetized with Zoletil $50^{\circledR}(10 \mathrm{mg} / \mathrm{kg}$, i.m.) 35 days after BCCAO, immediately after the probe trial. The perfusion and fixation were conducted as described above. The frozen brains were coronally sectioned on a cryostat at $30 \mu \mathrm{m}$ and then stored in a storage solution (30\% ethylene glycol, $30 \%$ glycerin, and $20 \mathrm{mM}$ phosphate buffer) at $4^{\circ} \mathrm{C}$. Hippocampal sections were collected based on the mouse brain atlas [13]. 


\section{Immunohistochemistry}

The free-floating sections were incubated for $24 \mathrm{~h}$ in PBS $\left(4^{\circ} \mathrm{C}\right)$ containing a rat anti-BrdU antibody (1:500), a rabbit anti-Ki67 antibody (1:1000) or a goat anti-DCX antibody (1:500), $0.3 \%$ Triton X-100, $0.5 \mathrm{mg} / \mathrm{ml}$ bovine serum albu$\mathrm{min}$, and $1.5 \%$ goat or rabbit serum from the $\mathrm{ABC}$ kit. The sections were then incubated for $90 \mathrm{~min}$ with a biotinylated secondary antibody (1:200), treated with the $A B C$ solution (1:100) for $1 \mathrm{~h}$ at room temperature, and reacted with $0.02 \% 3,3$ '-diaminobenzidine tetrahydrochloride (DAB) and $0.01 \% \mathrm{H}_{2} \mathrm{O}_{2}$ for approximately $3 \mathrm{~min}$. After each incubation step, the sections were washed three times with PBS for $5 \mathrm{~min}$. Finally, the sections were mounted on gelatincoated slides, dehydrated in an ascending alcohol series, and cleared in xylene.

For multiple staining, free-floating sections were rinsed extensively with PBS $(50 \mathrm{mM}, \mathrm{pH} 7.4)$ and then incubated for $30 \mathrm{~min}$ in $\mathrm{HCl}(2 \mathrm{~N})$ at $37^{\circ} \mathrm{C}$ to denature DNA. Serial procedures were then conducted as described above. The BrdU-labeled cells were visualized with $0.02 \% \mathrm{DAB}, 0.01 \% \mathrm{H}_{2} \mathrm{O}_{2}$, and $0.2 \%$ nickel ammonium sulfate in $50 \mathrm{mM}$ PBS for approximately $3 \mathrm{~min}$. The free-floating sections were then incubated for $24 \mathrm{~h}$ in $\mathrm{PBS}\left(4^{\circ} \mathrm{C}\right)$ containing a rabbit anti-glial fibrillary acidic protein (GFAP) antibody (1:1000), a mouse antineuronal nuclei $(\mathrm{NeuN})$ antibody $(1: 1000)$, or a goat anti-DCX antibody (1:500), as well as $0.3 \%$ Triton X100 and $2 \%$ donkey serum. The sections were then incubated for $90 \mathrm{~min}$ with a FITC- or Cy3-conjugated secondary antibody $(1: 200)$. After each incubation step, the sections were washed three times with PBS for $5 \mathrm{~min}$, finally, the sections were mounted on gelatincoated slides, overlaid with VECTASHIELD mounting medium, and covered with a coverslip.

\section{Western blot analysis}

For the preparation of Western blot samples, four mice were sacrificed immediately after the probe test of Morris water maze task, and their isolated hippocampal tissues were homogenized in an ice-cold Tris-HCl buffer $(20 \mathrm{mM}$, $\mathrm{pH}$ 7.4) containing $0.32 \mathrm{M}$ sucrose, $1 \mathrm{mM}$ EDTA, $1 \mathrm{mM}$ EGTA, 1 mM PMSF, a Complete Protease Inhibitor Cocktail (1 tablet $/ 50 \mathrm{ml})$ and a PhosSTOP Phosphatase Inhibitor Cocktail (1 tablet/10 ml). Samples of the homogenates (20 $\mu \mathrm{g}$ of protein) were then subjected to SDS-PAGE (8\%) under reducing conditions. The proteins were transferred to PVDF membranes in a transfer buffer [25 mM Tris-HCl buffer (pH 7.4) containing $192 \mathrm{mM}$ glycine and $20 \% \mathrm{v} / \mathrm{v}$ methanol] and further separated at $400 \mathrm{~mA}$ for $2 \mathrm{~h}$ at $4^{\circ} \mathrm{C}$. The Western blots were then incubated for $1 \mathrm{~h}$ with a blocking solution (5\% skim milk), then with rabbit anti-pAkt, rabbit anti-pGSK3 $\beta$, or rabbit anti- $\beta$-catenin (1:3000) antibody overnight at $4{ }^{\circ} \mathrm{C}$, washed ten times with Tween 20/Tris-buffered saline
(TTBS), incubated with a 1:2000 dilution of horseradish peroxidase-conjugated secondary antibodies for $2 \mathrm{~h}$ at room temperature, washed ten times with TTBS, and finally developed by enhanced chemiluminescence (Amersham Life Science, Arlington Heights, IL). The blots were then stripped and incubated with a rabbit anti-Akt, rabbit anti-GSK3 $\beta$ or goat anti-tubulin antibody (1:5000). The membrane was analyzed with the bio-imaging program of the LAS-4000 mini (Fujifilm Lifescience USA, Stamford, CT).

\section{Nissl staining}

After the sections were mounted onto gelatin-coated slides, they were stained with $0.5 \%$ cresyl violet, dehydrated through graded alcohols $(70,80,90$, and $100 \% \times 2)$, placed in xylene, and covered with a coverslip after the addition of Histomount media.

\section{Quantification and statistical analysis}

The number of cells in the hippocampal DG region was determined using a computerized image analysis system (Leica Microsystems AG, Wetzlar, Germany). The cells were counted in 6 sections by every 8 sections interval (total 48 sections) per animal by a person blind to the treatment group, and the average cell count per section was computed. The degree of damage in the hippocampal CA1 by the Nissl staining after ischemia was semiquantitatively scored from 0 to 3 ( 0 , normal; $1,<30 \%$ of the neurons were irreversibly damaged; $2,30-60 \%$ of the neurons were irreversibly damaged; $3,60-100 \%$ of the neurons were irreversibly damaged) as described elsewhere [14]. The values are expressed as the means \pm S.E. M. The results of histological, immunohistochemical, and Western blot analyses were analyzed using Student $t$-test or one-way analysis of variance (ANOVA) followed by Student Newman-Keuls's post-hoc test for multiple comparisons. Two-way ANOVA was used to analyze the data of the path length in the training trials of the Morris water maze task, and when the results were significant, Bonferroni's post-hoc test was used to compare the treatment groups. The statistical significance was set at $P<0.05$.

\section{Results}

DJS enhanced learning and memory in the passive avoidance test and BrdU incooperation

DJS (100 or $200 \mathrm{mg} / \mathrm{kg} /$ day, p.o.)-administered normal mice showed significant increase in step-through latency during the retention trial of the passive avoidance task $(P<0.05$, Figure $1 \mathrm{~A})$. However, there were no significant changes in step-through latency in the other treated groups (50 or $400 \mathrm{mg} / \mathrm{kg}$ ). We adopted $100 \mathrm{mg} / \mathrm{kg}$ of DJS for further study. Moreover, DJS administration $(100 \mathrm{mg} / \mathrm{kg} /$ day, p.o.) also increased the 


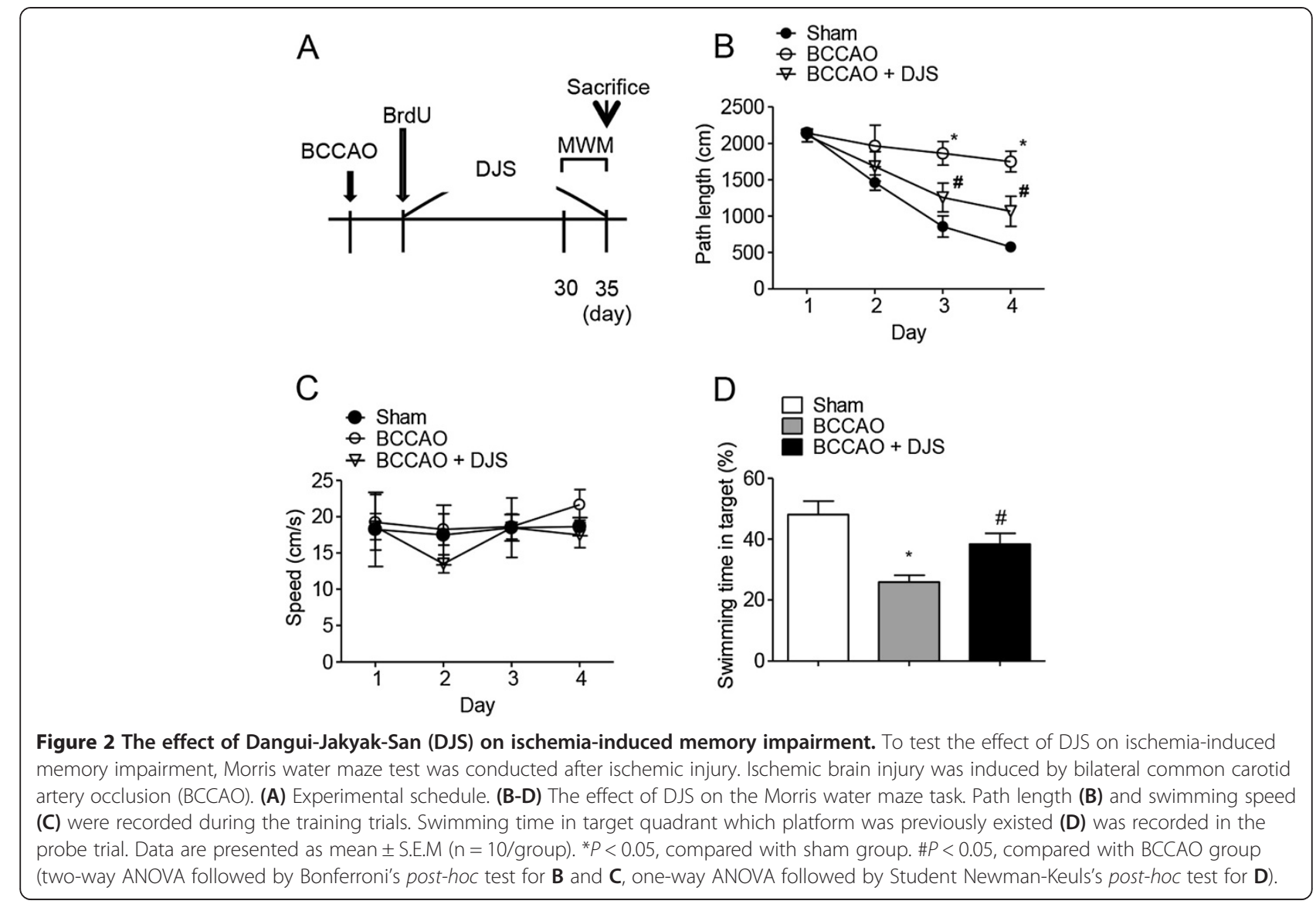

number of BrdU-positive cells in mouse hippocampal DG region $(P<0.05$; Figure $1 \mathrm{~B})$.

\section{Delayed DJS treatment ameliorated memory impairment induced by transient forebrain ischemia}

As shown in Figure 2B, DJS significantly shortened the path length $(P<0.05$; Figure $2 \mathrm{~B})$ in the training trials without affecting the swimming speed (Figure 2C). In the probe trial, the swimming times within the target quadrant in the DJS-treated group were significantly higher than those in the vehicle-treated control group $(P<0.05$, Figure 2D).

\section{Delayed DJS treatment increased neurogenesis}

In neural proliferation, cells positive for Ki67 were significantly increased in DJS-treated group compared with the other groups $(P<0.05$, Figure $3 \mathrm{~A}$ and $\mathrm{B})$. Moreover, DCX-positive cells were significantly increased by DJS treatment $(P<0.05$, Figure $3 \mathrm{~A}$ and $\mathrm{C})$. To test whether DJS has neuroprotective effect, we conducted Nissl staining of CA1 region which is well known as most vulnerable region in ischemic brain [15-17]. However, delayed DJS treatment did not protect neuronal injury induced by BCCAO $(P>0.05$, Figure $3 \mathrm{~A}$ and $\mathrm{D})$, suggesting that effect of DJS is not due to its protective effect. In neuronal differentiation, the DIS-treated BCCAO group showed significantly higher levels of BrdUpositive cells $(P<0.05$, Figure $3 \mathrm{~F}), \mathrm{BrdU}$ and NeuNdouble-positive cells $(P<0.05$, Figure $3 \mathrm{E}$ and $\mathrm{F})$, BrdU and DCX-double-positive cells $(P<0.05$, Figure $3 \mathrm{E}$, and $\mathrm{F}]$, and BrdU and GFAP-double-positive cells $(P<0.05$, Figure $3 \mathrm{E}$ and $3 \mathrm{~F}$ ) than those of the vehicle-treated $\mathrm{BCCAO}$ or sham groups. In addition, these neuronal differentiation markers were also slightly increased in the vehicle-treated BCCAO group. However, the propotions of each neural cell were not significantly different (Figure 3G).

\section{Delayed DJS treatment activated Akt/GSK3 $\beta / \beta$-catenin signaling}

In the hippocampi of the vehicle-treated BCCAO group, the expression levels of pAkt, pGSK3 $\beta$, and $\beta$-catenin were not significantly different from those of sham group. However, DJS treatment significantly increased these signaling molecules in the hippocampus $(P<0.05$, Figure 4A-D).

\section{Discussion}

There is still no successful treatment for massive neurodegenerative diseases such as ischemic stroke. Therefore, many researchers have been focusing on the regeneration 


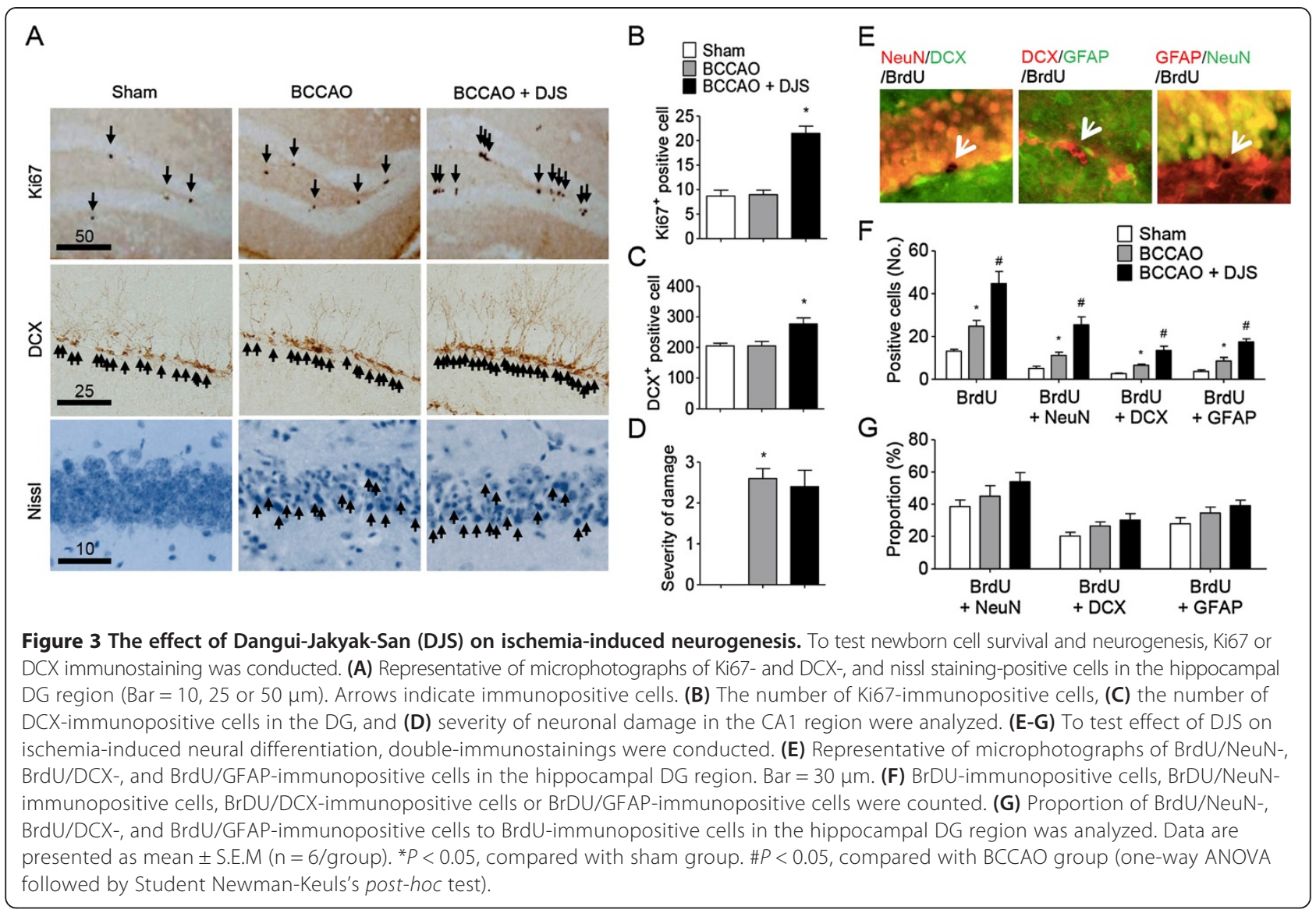

of tissue or neurons using embryonic stem cells. However, methods utilizing these cells are still under preclinical study due to insufficient knowledge about their physiology. Recent findings in rodent models of stroke that suggest the replacement of hippocampal pyramidal cells by endogenous progenitors raise optimism for regenerative therapies [18]. Before using endogenous neuronal progenitors for the treatment of brain ischemia, several issues should be addressed. First, to achieve the replacement of lost neurons, neuronal progenitors should first change the pathway towards the ischemic lesion, where constitutive neurogenesis does not normally occur (non-neurogenic regions). The second issue is that few neurons actually mature in the lesion, which would account for the difficulty of functional recovery after ischemic injury. It has also been questioned whether such new neurons become functionally active. Recently, these issues were addressed through various experiments. Previous report has already suggested that treatment with antidepressant and constituents of ginseng increased ischemic stroke-induced neurogenesis and improved the functional outcome [3]. Moreover, blockade of neurogenesis in ischemic brain exacerbates functional deficit [19]. They suggest that the increase of neurogenesis give a chance to overcome loss of neurons in ischemic vulnerable region. Therefore, these findings suggest that the increase of endogenous neurogenesis may be good target for repairing neurodegenerative diseases.

DJS has shown neuroprotective effect in various in vivo and in vitro conditions [6-12]. However, functional mechanisms of the effect of DIS on various neurological deficits are still not clarified. Previous reports indicated that DJS regulates neurotransmitters level including acetylcholine and monoamines, and reduces oxidative damage in various brain disease model $[8,11,20]$. In this study, we found that delayed long-term administration of DJS improves ischemic damage-induced spatial memory impairment. In addition, DJS significantly increased transient forebrain ischemia-induced hippocampal neurogenesis and attenuated memory impairment. Moreover, because delayed administration with DJS failed to rescue ischemia-induced neuronal cell death, we suggest that DIS-induced increase of neurogenesis may be a possible mechanism for functional improvement. However, it was found that DJS did not affect neuronal differentiation. Further research should be required to clarify this issue. While DJS showed its memory enhancing effect at 14-day treatment in normal naive mice, it showed its effect at 28-day but not at 14-day treatment in ischemic mice. The reasons of the differences are unclear, but we speculate that effective 


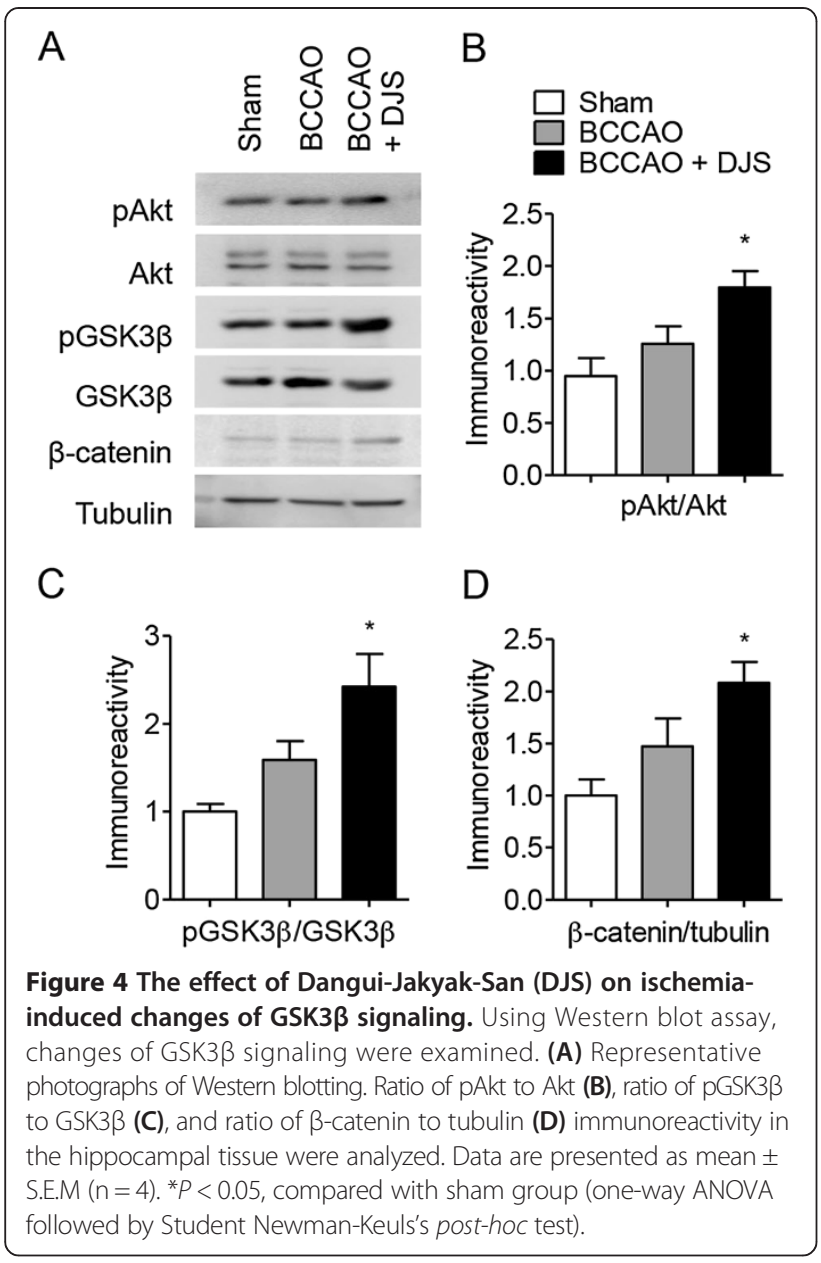

compounds, which are contained in DJS, are different in depends on conditions.

Recently, it has been suggested that GSK3 is a master regulator of neuronal progenitor homeostasis [21]. Changes in GSK3 $\beta$ activity occur after cerebral ischemia in regional, severity of injury, or model dependent manner: increase in cortical and striatal neurons after global ischemia [22]; decreases in the hippocampal CA1 but not CA3 region after global ischemia [23]. However, GSK3 $\beta$ activity has not been examined in the neurogenic regions including hippocampal DG and subventricular zone. In compatible with neurogenesis, DJS modulated ischemia-induced changes in Akt/ GSK3 $\beta / \beta$-catenin singaling. Appropriate regulation of $\beta$ catenin, which is a downstream molecule of GSK3 3 , is critical for the control of progenitior proliferation in various regions of the developing nervous system $[24,25]$. Therefore, GSK3 $\beta / \beta$-catenin signaling is to be one possible mechanism for DJS-induced neurogenesis.

\section{Conclusions}

Taken together, we propose that post-ischemic prolonged DJS administration ameliorates the memory impairment induced by transient forebrain ischemia via an increase of neurogenesis that is mediated by activation of hippocampal Akt/GSK3 $\beta / \beta$-catenin signaling. However, treatment should be conducted carefully because the effect of DJS is not promise in higher dose.

\section{Abbreviations}

DJS: Danggui-Jakyak-San; DG: Dentate gyrus; GSK3ß: Glycogen synthase kinase-3B; BrdU: 5-Bromo-2'-deoxyuridine; DCX: Doublecortin; ABC: Avidinbiotin-peroxidase complex; BCCAO: Bilateral common carotid artery occlusion; rCBF: regional cerebral blood flow; PBS: Phosphate-buffered saline; TTBS: Tris-buffered saline; ANOVA: One-way analysis of variance; GFAP: Glial fibrillary acidic protein; NeuN: Neuronal nuclei.

\section{Competing interests}

The authors declare no conflict of interests.

\section{Authors' contributions}

MDS designed and conducted all neurogenesis experiments. DHK and JMK conducted behavioural experiments. HEL and SJP conducted western blot and immunohistochemical experiments. JHR and JHL conceived of the study, participated in its design and coordination and helped to draft the manuscript. All authors read and approved the final manuscript.

\section{Acknowledgement}

This research was supported by Basic Science Research Program through the National Research Foundation of Korea (NRF) funded by MEST (2011-0010884).

\section{Author details}

${ }^{1}$ Graduate School of East-west Medical Science, Kyung Hee University, Yongin 446-701, Republic of Korea. ${ }^{2}$ Department of Life and Nanopharmaceutical Sciences, Kyung Hee University, Seoul 130-701, Republic of Korea. ${ }^{3}$ Department of Oriental Pharmaceutical Science, College of Pharmacy, Kyung Hee University, Seoul 130-701, Republic of Korea.

Received: 18 June 2013 Accepted: 19 November 2013 Published: 22 November 2013

\section{References}

1. Bengzon J, Kokaia Z, Elmer E, Nanobashvili A, Kokaia M, Lindvall O: Apoptosis and proliferation of dentate gyrus neurons after single and intermittent limbic seizures. Proc Natl Acad Sci U S A 1997, 94(19):10432-10437.

2. Sharp FR, Liu J, Bernabeu R: Neurogenesis following brain ischemia. Brain Res Dev Brain Res 2002, 134(1-2):23-30.

3. Li WL, Cai HH, Wang B, Chen L, Zhou QG, Luo CX, Liu N, Ding XS, Zhu DY: Chronic fluoxetine treatment improves ischemia-induced spatial cognitive deficits through increasing hippocampal neurogenesis after stroke. J Neurosci Res 2009, 87(1):112-122.

4. Liu P: Danggui-Shaoyao-san on central-hypothalamic-ovary-endocrine system. Chin Tradit Pat Med 1993, 15:30-32.

5. Zhou BH, Luo SD, Cai HS: Progress in pharmacological and clinical research of Danggui-Shaoyao-san. Chin Tradit Pat Med 1993, 15:38-40.

6. Kitabayashi Y, Shibata K, Nakamae T, Narumoto J, Fukui K: Effect of traditional Japanese herbal medicine toki-shakuyaku-san for mild cognitive impairment: SPECT study. Psychiatry Clin Neurosci 2007, 61(4):447-448.

7. Goto H, Satoh N, Hayashi Y, Hikiami H, Nagata Y, Obi R, Shimada Y: A chinese herbal medicine, tokishakuyakusan, reduces the worsening of impairments and independence after stroke: a 1-year randomized, controlled trial. Evid Based Complement Alternat Med 2011, 2011:194046.

8. Hatip-Al-Khatib I, Egashira N, Mishima K, Iwasaki K, Kurauchi K, Inui K, Ikeda T, Fujiwara M: Determination of the effectiveness of components of the herbal medicine Toki-Shakuyaku-San and fractions of Angelica acutiloba in improving the scopolamine-induced impairment of rat's spatial cognition in eight-armed radial maze test. J Pharmacol Sci 2004, 96(1):33-41.

9. Hu ZY, Liu G, Yuan H, Yang S, Zhou WX, Zhang YX, Qiao SY: DangguiShaoyao-San and its active fraction JD-30 improve Abeta-induced spatial recognition deficits in mice. J Ethnopharmacol 2010, 128(2):365-372.

10. Itoh T, Michijiri S, Murai S, Saito H, Nakamura K, Itsukaichi O, Fujiwara H, Ookubo N: Regulatory effect of danggui-shaoyao-san on central cholinergic nervous system dysfunction in mice. Am J Chin Med 1996, 24(3-4):205-217. 
11. Egashira N, Iwasaki K, Akiyoshi Y, Takagaki Y, Hatip-Al-Khatib I, Mishima K, Kurauchi K, Ikeda T, Fujiwara M: Protective effect of Toki-shakuyaku-san on amyloid $\beta$ 25-35-induced neuronal damage in cultured rat cortical neurons. Phytother Res 2005, 19(5):450-453.

12. Qian YF, Wang H, Yao WB, Gao XD: Aqueous extract of the Chinese medicine, Danggui-Shaoyao-San, inhibits apoptosis in hydrogen peroxide-induced $\mathrm{PC} 12$ cells by preventing cytochrome $\mathrm{c}$ release and inactivating of caspase cascade. Cell Biol Int 2008, 32(2):304-311.

13. Paxinos G, Franklin KBJ: The mouse barin in stereotaxic coordinates. San Diago: Acedemic Press; 2001.

14. Cho KO, Kim SK, Cho YJ, Sung KW, Kim SY: Regional differences in the neuroprotective effect of minocycline in a mouse model of global forebrain ischemia. Life Sci 2007, 80(22):2030-2035.

15. Murakami K, Kondo T, Kawase M, Chan PH: The development of a new mouse model of global ischemia: focus on the relationships between ischemia duration, anesthesia, cerebral vasculature, and neuronal injury following global ischemia in mice. Brain Res 1998, 780(2):304-310.

16. Kelly S, McCulloch J, Horsburgh K: Minimal ischaemic neuronal damage and HSP70 expression in MF1 strain mice following bilateral common carotid artery occlusion. Brain Res 2001, 914(1-2):185-195.

17. Wu C, Zhan RZ, Qi S, Fujihara H, Taga K, Shimoji K: A forebrain ischemic preconditioning model established in C57Black/Crj6 mice. J Neurosci Methods 2001, 107(1-2):101-106.

18. Zhang Z, Yang R, Cai W, Bai Y, Sokabe M, Chen L: Treatment with progesterone after focal cerebral ischemia suppresses proliferation of progenitor cells but enhances survival of newborn neurons in adult male mice. Neuropharmacology 2010, 58(6):930-939.

19. Raber J, Fan Y, Matsumori Y, Liu Z, Weinstein PR, Fike JR, Liu J: Irradiation attenuates neurogenesis and exacerbates ischemia-induced deficits. Ann Neurol 2004, 55(3):381-389.

20. Komatsu M, Ueda $Y$, Hiramatsu M: Different changes in concentrations of monoamines and their metabolites and amino acids in various brain regions by the herbal medicine/Toki-Shakuyaku-San between female and male senescence-accelerated mice (SAMP8). Neurochem Res 1999, 24(7):825-831.

21. Kim WY, Wang X, Wu Y, Doble BW, Patel S, Woodgett JR, Snider WD: GSK-3 is a master regulator of neural progenitor homeostasis. Nat NeurosCi 2009, 12(11):1390-1397.

22. Bhat RV, Shanley J, Correll MP, Fieles WE, Keith RA, Scott CW, Lee CM: Regulation and localization of tyrosine216 phosphorylation of glycogen synthase kinase-3 3 in cellular and animal models of neuronal degeneration. Proc Natl Acad Sci U S A 2000, 97(20):11074-11079.

23. Endo H, Nito C, Kamada H, Nishi T, Chan PH: Activation of the Akt/GSK3ß signaling pathway mediates survival of vulnerable hippocampal neurons after transient global cerebral ischemia in rats. $J$ Cereb Blood Flow Metab 2006, 26(12):1479-1489.

24. Gulacsi AA, Anderson SA: $\beta$-catenin-mediated Wnt signaling regulates neurogenesis in the ventral telencephalon. Nat Neurosci 2008, 11(12):1383-1391.

25. Mao Y, Ge X, Frank CL, Madison JM, Koehler AN, Doud MK, Tassa C, Berry EM, Soda T, Singh KK, et al: Disrupted in schizophrenia 1 regulates neuronal progenitor proliferation via modulation of GSK3 $\beta / \beta$-catenin signaling. Cell 2009, 136(6):1017-1031.

doi:10.1186/1472-6882-13-324

Cite this article as: Song et al:: Danggui-Jakyak-San ameliorates memory impairment and increase neurogenesis induced by transient forebrain ischemia in mice. BMC Complementary and Alternative Medicine 2013 13:324.

\section{Submit your next manuscript to BioMed Central and take full advantage of:}

- Convenient online submission

- Thorough peer review

- No space constraints or color figure charges

- Immediate publication on acceptance

- Inclusion in PubMed, CAS, Scopus and Google Scholar

- Research which is freely available for redistribution 